\section{La revista JAMA dedicará el número de agosto de 1999 a la epidemia de violencia}

Hoy en día los líderes internacionales en medicina y salud pública han llegado a reconocer que la violencia es un riesgo de salud de alcance universal. El Banco Mundial, al intentar cuantificar la carga mundial de enfermedad, ha incluido los factores de violencia que afectan negativamente al estado de la salud en todo el mundo: los accidentes de automóviles, las caídas, el homicidio, el suicidio y la guerra. Esos intentos han suscitado críticas y controversia, pero organismos de salud pública tan importantes como la Organización Mundial de la Salud, el Instituto de Medicina y los Centros para el Control y la Prevención de Enfermedades de los Estados Unidos de América se han pronunciado a favor de declarar que la violencia merece atención prioritaria en salud pública. Muchas revistas médicas conmemoraron el cincuentenario de la Declaración Universal de Derechos Humanos publicando una variedad de artículos sobre los efectos de la violencia. De modo que la violencia ha dejado de enfocarse indirectamente y de esconderse tras apelativos como "cuestión de salud pública controvertida" y "hecho inevitable de la vida" para reconocerse como una epidemia soslayada que pronto superará a las enfermedades infecciosas como causa principal de morbilidad y mortalidad prematura en todo el mundo.

La OMS y el Banco Mundial han estimado que los actos de violencia contribuyen 15\% de la carga mundial de enfermedad, pero no existen indicadores adecuados para medir su impacto total. Considérese que las tasas de mortalidad por homicidio y suicidio, que son fáciles de obtener y sirven para hacer ciertas comparaciones entre países, no incluyen las muertes no registradas relacionadas con la violencia. Ejemplo de ello son las que ocurren como resultado de conflictos civiles y el desplazamiento masivo de refugiados, así como las muertes relacionadas con la violencia atribuidas por error a otras causas. De modo similar, las estadísticas vitales registradas en hospitales, clínicas, departamentos de policía, gobiernos locales y nacionales, y organizaciones no gubernamentales son incompletas, pues no pueden incluir la información que se omite del registro público por temor a represalias o estigmatización. Además, las tasas totales de mortalidad pueden encubrir el efecto de la violencia en subgru- pos vulnerables - como los civiles, especialmente mujeres y niños, y los pobres - y no miden apropiadamente los efectos indirectos de la violencia en la salud del individuo, la familia y la comunidad.

Con objeto de promover investigaciones que intenten cuantificar los efectos directos e indirectos de la violencia y evaluar las formas de prevención y de intervención, la revista JAMA dedicará su número del 4 de agosto de 1999 a este tema, en conmemoración de la destrucción nuclear de Hiroshima. Se aceptarán trabajos sobre una amplia gama de temas relacionados con la violencia, como la amenaza que plantean las armas de fuego para la salud pública, la violencia interpersonal, los conflictos civiles y la guerra, las armas de destrucción en masa, la migración en masa y el desplazamiento forzado de refugiados, la tortura y otras violaciones de los derechos humanos básicos. Se dará prioridad a los informes de calidad sobre investigaciones originales. Interesan también las revisiones sistemáticas y los comentarios. Todos los manuscritos se someterán a evaluación editorial y revisión por expertos. En la preparación y presentación de manuscritos deberán acatarse las instrucciones a los autores que publica la revista. (Flanagin A, Cole TB. Violence, a neglected epidemic: call for papers. JAMA 1998; 280(24):2121.)

\section{El maltrato de las mujeres en edad fecunda en Nicaragua}

El maltrato de la mujer por el marido es un problema de salud pública cada vez más preocupante en todas partes del mundo. Si bien no hay muchos datos sobre su prevalencia, se ha estimado que en la mayor parte de los países entre 20 y 50\% de las mujeres han sido maltratadas físicamente por su compañero de intimidad. El maltrato de la mujer está asociado con una variedad de resultados de salud desfavorables tanto para la mujer como para sus hijos; entre ellos trauma, bajo peso al nacer, padecimientos ginecológicos, depresión, suicidio y enfermedades de transmisión sexual. Son pocos los estudios que mencionan factores de riesgo significativos que apunten hacia el maltrato de la mujer, pero algunos se han asociado repetidamente con la violencia en el varón; por ejemplo, haber presenciado actos de violencia en la niñez, la pobreza, el estrés, el consumo de alcohol y las normas cultura- 
les que discriminan contra la mujer. En Nicaragua ha aumentado considerablemente la conciencia del problema, lo que se debe en parte al número cada vez mayor de organizaciones gubernamentales que proporcionan servicios de salud, psicológicos y legales a las mujeres maltratadas, y trabajan para mejorar las leyes y la política pública relacionadas con la violencia en el hogar. Aunque la incidencia del maltrato de la mujer por el compañero ha aumentado, por falta de datos poblacionales no se sabe si ello refleja un verdadero aumento o la mejor disponibilidad de información.

En la primera encuesta poblacional llevada a cabo en Nicaragua sobre este tema se midieron la prevalencia, la frecuencia e intensidad del maltrato físico de la mujer y los factores de riesgo asociados. Ese estudio transversal se basó en una muestra representativa de 488 mujeres de 15 a 49 años de edad residentes en León, la segunda ciudad del país en tamaño, con una población de 195000 habitantes. La prevalencia y la intensidad de la violencia se midieron con la escala denominada Conflict Tactics Scale [Escala de Tácticas de Conflicto], que se considera de alta validez conceptual para ese tipo de estudios. En ella se clasifican ocho actos según su gravedad. Se consideran actos de mediana violencia empujar a la persona, abofetearla y arrojarle objetos; y de intensa violencia darle puntapiés, pegarle con el puño cerrado, pegarle con algún objeto, darle "una paliza" o amenazarla con un cuchillo o arma de fuego. El maltrato se definió como haber experimentado en cualquier momento uno o más actos de violencia física a manos del compañero de intimidad presente o pasado. Se usó un cuestionario para recoger la información sobre escolaridad y datos familiares. El nivel socioeconómico se midió mediante la valoración de necesidades básicas. Todas las participantes fueron entrevistadas en privado por trabajadoras que habían recibido instrucción apropiada y a todas se les entregó un folleto educativo sobre la violencia doméstica y se les ofreció orientación personal gratuita.

Entre las 360 mujeres que habían estado casadas alguna vez, la prevalencia de la violencia por parte del compañero durante el ciclo de vida ascendió a $52 \%$. Además, $27 \%$ habían experimentado violencia en los 12 meses anteriores. La violencia se asoció significativamente con la pobreza, tener más de cuatro hijos, vivir en la ciudad y antecedentes de violencia en la familia de ella o del marido. No se hallaron asociaciones significativas entre la violencia y la edad, escolaridad, dependencia marital u ocupación de la mujer. Los autores concluyen que el maltrato de la esposa constituye un grave problema de salud pública en Nicaragua y es preciso tomar medidas urgentes para prevenirlo y tratar a las víctimas. (Ellsberg MC, Peña R, Herrera A, Lil- jestrand J, Winkvist A. Wife abuse among women of childbearing age in Nicaragua. Am J Public Health 1999;89:241-244).

\section{Secuelas psicológicas de la represión política en niños hondureños}

Durante los decenios de 1970 y 1980, en muchos países de América Latina con regímenes de gobierno represivos, millares de disidentes políticos fueron secuestrados, torturados, encarcelados en lugares clandestinos y finalmente asesinados o hechos "desaparecer". Se han realizado pocos estudios sobre los efectos de esa violencia en los supervivientes, pero una investigación llevada a cabo en niños hondureños en 1992 y 1993 enfoca los efectos psicológicos de la pérdida del padre ( $\mathrm{y}$ en un caso de la madre) en esas circunstancias. En ese estudio se entrevistó a 16 niños cuyos padres "desaparecieron" y a 11 cuyos padres habían sido asesinados, así como a sus guardianes. El contacto con las familias fue posible por mediación del Comité de Familiares de Detenidos-Desaparecidos en Honduras (COFADEH). En las entrevistas con los niños, que contaban con 14 a $15^{1} / 2$ años de edad, se usaron tres instrumentos que incluían preguntas semiestructuradas y abiertas sobre el impacto emocional, social y familiar de la pérdida y la represión: la lista de reacciones al estrés postraumático conocida como post-traumatic stress reaction checklist (PTSRC), la escala del inventario de comportamientos de los niños o child behavior inventory y la escala MOA para la prueba de Rorschach. En la interpretación de esta prueba trabajaron independientemente dos personas, que lograron un acuerdo exacto de $93 \%$, y una tercera persona que resolvió las diferencias.

Pese a que los integrantes de ambos grupos estudiados eran muy heterogéneos en escolaridad, ocupación, vivienda e ingresos, en todos el ingreso familiar había disminuido sustancialmente a partir de la pérdida del padre. La mayoría de los entrevistados sentían inseguridad económica y privación o pobreza. En la búsqueda de los seres queridos desaparecidos o al enterrar a los asesinados, todos habían tenido que hacer frente a gastos enormes sin recibir ayuda económica, compensación ni beneficios. La mayoría de los niños indicaron que sentían una discontinuidad en su vida, que eran diferentes de los demás, que estaban solos, dañados y llenos de sufrimiento psíquico. Sentían gran inseguridad y preocupación por el futuro, temían perder lo que tenían, sobre todo a sus familias, y pensaban que les esperaban experiencias dolorosas. No podían hablar con nadie de lo que había ocurrido y con frecuencia sentían ira y agresividad, aunque esos sentimientos no se expresaran. La mayor parte de los 
guardianes opinaban que los desaparecidos habían muerto, pero los niños se aferraban mucho más a la ilusión de que sus padres pudieran estar vivos todavía. Sin embargo, tanto los mayores como los niños mostraron contradicciones en ese sentido. Los niños de padres desaparecidos sentían más conflictos familiares, perturbaciones subconscientes y trauma que los de padres asesinados y esto se reveló especialmente en las pruebas de Rorschach.

Se aduce que los hijos de padres asesinados tienen un conocimiento definitivo que les permite llorar por sus seres queridos y llegar a cierta resolución de su pérdida. Los de padres desaparecidos están obligados a funcionar en una zona ambigua de cuasipsicosis y necesitan desesperadamente saber cuándo, cómo, dónde y por qué sucedió la tragedia. En este estudio se destacaron dos resultados inesperados: 1) el tiempo transcurrido había disminuido muy poco los síntomas de trauma en los niños con padres desaparecidos y 2) en ese grupo predominaba también una mayor perturbación emocional que en los hijos de padres asesinados. Ambos grupos de niños hondureños y sus familias han sido irrevocablemente afectados por la pérdida de un miembro de la familia, las circunstancias en torno a esa pérdida, la hostilidad y persecución que ellos mismos han sufrido y los problemas económicos y de aislamiento social que agravan su situación. (Munczek DS, Tuber S. Political repression and its psychological effects on Honduran children. Soc Sci Med 1998;47(11):1699-1713).

\section{Los niños de la calle y la violencia en el Brasil}

La presencia de un gran número de niños desprotegidos y sin supervisión es un fenómeno común en las calles de América Latina. En pocos lugares son esos niños tan visibles y deplorados como en el Brasil, donde entre 7 y 8 millones de niños de 5 a 18 años de edad viven y trabajan en las calles de las ciudades. Numerosos estudios científicos y reportajes verifican el extenso consumo entre ellos de inhalantes, marihuana, cocaína y Rohypnol. La exposición al virus de la inmunodeficiencia humana (VIH) es un área de creciente preocupación debido al gran número de jóvenes callejeros que participan sin protección en actos sexuales remunerados y no remunerados. Lo peor es que los niños callejeros del Brasil, por su uso de drogas, crímenes predatorios y comportamiento inaceptable en general, son objeto de persecución violenta por parte de grupos locales de "vigilantes", bandas relacionadas con el comercio de drogas y "brigadas policíacas de la muerte". No deja de sorprender que pese a las muchas propuestas para aliviar el problema, el progreso haya sido insignificante. Con US\$ 2770 per cápita, Brasil tiene el producto nacional bruto más alto de América Latina (excepto por el Uruguay) y su economía es la décima del mundo en importancia. No obstante, tiene la distribución de recursos más desequilibrada del mundo: en 1996 el 10\% más rico de la población tuvo un ingreso 30 veces más alto que el ingreso medio del $40 \%$ más pobre, proporción que equivale a 10:1 en la Argentina, 9:1 en los Estados Unidos de América y 5:1 en los países de Europa. Los indicadores sociales y de salud y el estándar de vida están entre los más bajos de todo el continente, casi la mitad de todas las familias del país viven por debajo del límite de la pobreza (con $88 \%$ del salario mínimo) y casi una tercera parte son indigentes (con $53 \%$ del salario mínimo). Más de $18 \%$ de la población es analfabeta y 35\% de los niños de 7 a 15 años de edad no asisten a la escuela. El Brasil tiene la prevalencia más alta de malnutrición de América Latina, con excepción de Haití y Guatemala, y en 1993 la mortalidad infantil era de 52 por 1000 nacidos vivos, tasa excedida solamente por las del Perú (88) y Bolivia (98). Hay quienes explican estas inequidades por diferencias regionales y de discriminación racial, ya que el Brasil tiene la población negra más extensa fuera de África (70 millones o $46 \%$ del total) y en ella cunden el desempleo y la miseria. Como consecuencia de esas disparidades, ha habido una migración en masa de las zonas rurales a las urbanas, en donde los sectores de la educación, la salud y el empleo no han podido absorber a los millones de inmigrantes. Esta situación empuja a muchos niños y adolescentes a la calle para buscar las formas de contribuir al ingreso familiar o desvincularse totalmente del hogar. Mientras que la mayoría son varones, el gobierno estima que hay unas 800000 niñas que también trabajan en la calle, principalmente de prostitutas.

La tremenda violencia que acompaña la vida de los niños de la calle a menudo empieza en el hogar y los motiva a escaparse. Una vez en la calle, la violencia de índole sexual es muy común y niños de ambos sexos suelen ser violados por la policía y otros que se aprovechan de su vulnerabilidad. La violencia sexual se manifiesta entre ellos mismos y los más grandes obligan a los pequeños a tener relaciones sexuales con ellos. Según estimaciones de la OMS, entre 50000 y 100000 de esos niños y adolescentes están infectados por VIH. Lamentablemente, la población general se pone de parte de los comerciantes, policías, etc. que persiguen y asesinan a esos niños, pues lo consideran un tipo de "limpieza social". Se estima que cuatro o cinco niños callejeros mueren asesinados diariamente en el Brasil, dos en Río de Janeiro solamente. Ha habido muchas intervenciones sin éxito, por lo general de cuatro tipos. El enfoque correccional ha resultado en el interna- 
miento de miles de niños en instituciones hacinadas y abusivas. El enfoque de la rehabilitación ha ganado partidarios recientemente, pero no logra ampliar los programas de destoxificación, vivienda, trabajo y educación a los millones que los necesitan. También hay algunos servicios extrainstitucionales, como los que ofrece la iglesia católica de educar a los niños de la calle y capacitarlos para que puedan resolver sus problemas. Este modelo es demasiado ideológico y no aborda los peligros físicos inmediatos que amenazan a esos niños. Por último, el enfoque preventivo del UNICEF está dirigido al problema subyacente de la pobreza y se basa en actividades, educación y empleo para los niños y la prevención de la desintegración de la familia. El esfuerzo más intenso a favor de los niños de la calle es el Movimiento Nacional de Meninos e Meninas de Rua, una coalición de niños de la calle y adultos fundada en 1985 que trata de separar el problema del sistema de la justicia criminal, codificar y legalizar los derechos de los niños y estructurar nuevas formas de proporcionarles educación y entrenamiento en las mismas calles donde viven. Mientras tanto, su número aumenta. (Inciardi JA, Surratt HL. Children in the streets of Brazil: drug use, crime, violence, and HIV risks. Subst Use Misuse; 1998;33(7):1461-1480).

\section{La violencia en los medios de comunicación de los Estados Unidos de América}

En los años cincuenta se había planteado la posibilidad de que los programas de televisión que mostraban violencia tuvieran un impacto deletéreo en los niños, pero solo en los últimos años se ha llegado a reconocer como una cuestión de salud pública. Muchas encuestas nacionales han indicado la preocupación que siente al respecto la mayoría de los ciudadanos y hay numerosos estudios que muestran los efectos de la brutalidad televisada en la forma de una mayor agresividad, temores y desensibilización hacia la violencia en los niños y adolescentes. Desde 1995 se ha llevado a cabo un estudio nacional sobre la violencia en la televisión comisionado por la National Cable Television Association. El análisis prospectivo de una amplia gama de programas tiene dos objetivos principales: 1) identificar los rasgos contextuales de caracterizaciones violentas que puedan tener un impacto dañino y 2) analizar con profundidad el panorama de la televisión, sobre todo en cuanto a las caracterizaciones más problemáticas. Esta investigación se emprendió como una oportunidad para que la industria de la televisión pudiera mejorar su influencia en la sociedad distinguiendo entre caracterizaciones dañinas y beneficiosas de la violencia. Con este fin, la violencia se definió como la presentación mani- fiesta del uso de fuerza física o de la amenaza de su uso con la intención de hacerle daño a algún ser animado. La definición incluye las consecuencias físicas perjudiciales contra seres animados que resultan de presuntos medios violentos: amenazas verosímiles, actos de agresión y consecuencias perjudiciales de violencia no presenciada. En cuanto a rasgos contextuales, los resultados indican que en la programación de la televisión abundan los temas violentos o de acción violenta (aunque el tema sea la antiviolencia), en la presentación realista de actos violentos, la violencia que no se castiga, la presentación de heridas y sangre, las interacciones violentas que no parecen producir dolor o sufrimiento o que parecen justificadas, el uso de armas de fuego, y los perpretadores y víctimas atractivos. En $25 \%$ de todas las escenas violentas en las que se usan armas de fuego, la violencia casi siempre queda sin castigar; y $73 \%$ de los perpetradores de actos violentos no sufren consecuencias negativas por sus actos. Solo $16 \%$ de los programas indican las consecuencias negativas del comportamiento violento. Los programas para los niños son los que menos muestran consecuencias o el castigo (5\%) y en ellos las escenas violentas se presentan como humorísticas. Muy pocos programas condenan el uso de la violencia. De los programas violentos, solo $15 \%$ se acompañan de algún código orientador sobre el contenido; por otra parte, esa forma de categorización atrae sobre todo a los televidentes masculinos de 10 a 14 años de edad. Se observó que las películas presentan la violencia de forma más realista que los programas de televisión y que los canales públicos tienen menos violencia que los de cable.

El estudio tiene implicaciones importantes, ya que la noción de violencia justificable es muy seductora para los televidentes jóvenes e impresionables. Es mucho más probable que se imite la violencia caracterizada como "buena" y que no se castiga. Los investigadores concluyeron que existe una amenaza sustancial de efectos deletéreos en la presentación de la violencia por televisión. Sin embargo, se encontraron muchos otros mensajes negativos en los programas y películas, por ejemplo, los estereotipos del hombre (fuerte, mayor, decisivo) y la mujer (bonita, hogareña, romántica) y el ejemplo que constituyen para el comportamiento sexual futuro de los niños. Las niñas adolescentes se presentan como casquivanas y totalmente preocupadas por su apariencia física y las mujeres inteligentes, como inadaptadas. Los niños que ven mucha TV tienden a pensar que los varones deben jugar con revólveres de juguete y camiones y las niñas con muñecas. En los vídeos musicales y juegos, la sexualidad es excesiva y gran parte de la violencia está dirigida contra la mujer. En cuanto a la música popular, los temas incluyen sadismo, masoquismo, 
incesto, devaluación de la mujer y las drogas, y el alcohol y el suicidio como soluciones para los problemas cotidianos.

Todos esos medios tienen una gran influencia en los niños y adolescentes y podrían usarse para transmitir mensajes prosociales. Podrían fácilmente contribuir a la socialización y educación de los niños, a desarrollar su capacidad cognoscitiva y a complementar su aprendizaje escolar. Podrían igualmente promover la buena información sobre nutrición y salud y mejorar el uso de la tecnología electrónica, la resolución de problemas y numerosas otras habilidades. La violencia no debe tener ningún lugar en los medios dirigidos a las masas, a menos que se presente para ilustrar consecuencias negativas como el dolor que causa y el castigo que merece, o formas alternativas de lidiar con los conflictos. (Willis E, Strasburger VC. Media violence. Pediatr Clin North Am 1998;45(2):319-331).

\section{El culto de la violencia}

En los Estados Unidos de América el homicidio es la segunda causa de muerte en varones adolescentes, en quienes las armas de fuego causan más muertes que todas las enfermedades combinadas. $\mathrm{Si}$ bien las tasas de crímenes, tanto adultos como juveniles, se han reducido en el decenio de los noventa, el número de niños y adolescentes muertos por armas de fuego ha aumentado en 153\% desde 1985 hasta 1995. El crimen juvenil se ha vuelto cada vez más violento, los asesinos son cada vez más jóvenes y las armas de fuego son el medio preferido de cometer los actos de violencia. Esta situación no representa un nuevo fenómeno en la historia. Si se considera que la guerra es la forma más organizada de violencia, desde los hoplitas griegos, jenízaros turcos y húsaros polacos hasta los granaderos de Napoleón y selectos Waffen-SS de Hitler, siempre han sido los jóvenes y casi exclusivamente los varones quienes han cometido los actos de violencia y atrocidades. Hoy en día, desde Rwanda hasta Kosovo, son a menudo los jóvenes y aun hasta los niños quienes matan siguiendo la dirección y los prejuicios de sus mayores. Las razones de ese comportamiento son una incógnita, ya sea la perpetuación de "genes asesinos ancestrales", la ritualización prehistórica del temor a los predadores, las concentraciones de testosterona o la desintegración de la familia y la sociedad. Lo que hay en común es una sociedad permisiva con valores que consienten y favorecen - aunque sea tácitamente-, la violencia como forma natural y aceptable de conducta para alcanzar objetivos personales, políticos o económicos.

Puede que exista una fuerte predeterminación biológica, pero el comportamiento violento esencial es tan aprendido como los prejuicios, el odio, la compasión o la responsabilidad. Aun entre los niños más pequeños se observa una leve conducta violenta de carácter limitado, pero por medio de la socialización y el control progresivo de los impulsos el niño se desarrolla moralmente hasta comprender la diferencia entre el bien y el mal y los valores aprobados por la sociedad. Tradicionalmente, la familia y la sociedad han proporcionado los modelos de desarrollo. Hoy en día hay estudios muy persuasivos que sugieren que, en la transferencia de rasgos morales y sociales, "el ambiente no compartido" relacionado con los grupos de iguales es más importante que "el ambiente compartido" de la familia, la escuela y la iglesia. Es decir, que los padres y otras figuras de autoridad han perdido gran parte de su influencia en la determinación del desarrollo del niño y el adolescente. Otra influencia poderosa sobre la mente joven es la de los medios de comunicación y entrenamiento, en los que el deseo de lucro ha determinado que prime el voyeurismo de la violencia. Es muy difícil, si no imposible, controlar la exposición de los niños a las rápidas y numerosas escenas de violencia que aparecen día tras día en las pantallas de televisión, se evocan en la música popular y se ilustran con todo lujo de detalles en las tiras cómicas y los juegos de vídeo. El niño promedio llegará a adulto después de haber presenciado miles de actos violentos y asesinatos en esos medios. La repetición no solo avala ese comportamiento sino que disminuye la capacidad de las imágenes para perturbar y horrorizar. Lo más natural es que ello resulte en el comportamiento autoprotector de desensibilizarse y sentir indiferencia hacia el sufrimiento y la muerte e incapacidad para apreciar los finos matices de la moralidad, los valores sociales, la verdad y la empatía por los demás. La conducta violenta se convierte en una forma aceptable de vengarse, obtener respeto y la propiedad ajena, concluir las disputas y expresar las frustraciones. El componente final de la ecuación de la violencia es la disponibilidad de armas de fuego acumuladas por familias y vecinos. A una juventud inquieta se suma el culto a la violencia y se multiplica por la asequibilidad de armas de fuego, y el resultado es un aumento de la violencia perpetrada en los hogares, las escuelas y las calles por personas cada vez más jóvenes, violentas y mejor armadas. La violencia es la conducta humana más perversa y debe considerarse una enfermedad tan grave como cualquier otra, contra la cual es preciso combatir. (Stuk JP. The cult of violence. KMAJ 1993;96:497-498).

\section{Consumo de bebidas alcohólicas y violencia}

El consumo en exceso de bebidas alcohólicas es un problema muy difundido que implica proble- 
mas individuales de intregración social, pérdida de oportunidades de trabajo y menos años de vida saludable. Sus efectos son muy perjudiciales también para la familia y la comunidad. En México se calcula que el abuso del consumo de alcohol por sí solo significa $9 \%$ de la carga total de enfermedad. Además del alto porcentaje (39\%) de cirrosis hepática que provoca, el alcoholismo es una de las causas principales de lesiones por accidentes de vehículos de motor y actos de violencia. Sin embargo, el control de este problema es una de las nueve acciones de salud pública más costo-efectivas junto con los programas de control del tabaquismo, salud escolar, información sobre la salud, nutrición, planificación familiar y control de vectores. Por esas razones, el Instituto Mexicano de Psiquiatría, con el apoyo de la Secretaría de Salud y de la Dirección General de Servicios de Salud del estado de Hidalgo, inició en 1996 una investigación de gran envergadura sobre el consumo de alcohol y sus consecuencias en dicho estado. Como parte del proyecto, se llevó a cabo un estudio de la prevalencia del consumo y el abuso de las bebidas alcohólicas entre 1511 pacientes de 18 a 65 años de edad $-52,5$ hombres y 47,5 mujeres - atendidos en las salas de urgencias de tres hospitales generales de Pachuca, ciudad de mediano tamaño. Se usaron cuestionarios para recoger datos demográficos de los pacientes y escalas como CAGE y Alcohol Use Disorders Identification Test (AUDIT) para medir el grado individual de dependencia del alcohol. Además, se midió el alcohol en sangre de las personas que solicitaron atención por primera vez en esos servicios. Por medio de la prueba de ji al cuadrado $\left(\chi^{2}\right)$ se comparó el consumo de alcohol entre los pacientes que ingresaron por un accidente $\mathrm{o}$ acto de violencia y los que ingresaron debido a una urgencia médica. El consumo fue mayor y más frecuente en los pacientes que habían sufrido un accidente o acto de violencia que en los demás; $17,7 \%$ fueron positivos al alcosensor y 15,8\% notificaron consumo de alcohol en las 6 horas previas al incidente. Con las escalas CAGE y AUDIT se detectaron 9,2 y 10,9\%, respectivamente, de adictos al alcohol y bebedores asiduos. Casi 10\% de los pacientes que habían tenido accidentes o experimentado actos de violencia informaron que se habían embriagado más de una vez al mes durante el año anterior.

Se concluyó que el consumo de bebidas alcohólicas en los pacientes atendidos en los servicios de urgencias debido a accidentes o actos de violencia es elevado y reprenta una pesada carga para los servicios de salud. Deben tomarse medidas preventivas para disminuir el costo individual y social de esa conducta. Es necesario aprovechar la consulta médica para intervenir, ya que en muchos casos la situación es reversible. (Borges G, Medina-Mora ME, Cherpitel C, Casanova L, Mondragón L, Romero M. Consumo de bebidas alcohólicas en pacientes de los servicios de urgencias de la ciudad de Pachuca, Hidalgo. Salud Publica Mex 1999;41(1):3-11). 